\title{
Carbon Fiber Reinforced Polymer with Shredded Fibers: Quasi-Isotropic Material Properties and Antenna Performance
}

\author{
Gerald Artner, ${ }^{1,2}$ Philipp K. Gentner, ${ }^{1,2}$ Johann Nicolics, ${ }^{3}$ \\ and Christoph F. Mecklenbräuker ${ }^{1,2}$ \\ ${ }^{1}$ The Christian Doppler Laboratory for Wireless Technologies for Sustainable Mobility, Vienna, Austria \\ ${ }^{2}$ Institute of Telecommunications, Technische Universität Wien, Vienna, Austria \\ ${ }^{3}$ The Institute of Sensor and Actuator Systems, Technische Universität Wien, Wien, Austria \\ Correspondence should be addressed to Gerald Artner; gerald.artner@nt.tuwien.ac.at
}

Received 19 January 2017; Revised 6 April 2017; Accepted 20 April 2017; Published 29 May 2017

Academic Editor: Mirko Barbuto

Copyright (C) 2017 Gerald Artner et al. This is an open access article distributed under the Creative Commons Attribution License, which permits unrestricted use, distribution, and reproduction in any medium, provided the original work is properly cited.

\begin{abstract}
A carbon fiber reinforced polymer (CFRP) laminate, with the top layer consisting of shredded fibers, is proposed and manufactured. The shredded fibers are aligned randomly on the surface to achieve a more isotropic conductivity, as is desired in antenna applications. Moreover, fiber shreds can be recycled from carbon fiber composites. Conductivity, permittivity, and permeability are obtained with the Nicolson-Ross-Weir method from material samples measured inside rectangular waveguides in the frequency range of 4 to $6 \mathrm{GHz}$. The decrease in material anisotropy results in negligible influence on antennas. This is shown by measuring the proposed CFRP as ground plane material for both a narrowband wire monopole antenna for $5.9 \mathrm{GHz}$ and an ultrawideband conical monopole antenna for 1-10 GHz. For comparison, all measurements are repeated with a twill-weave CFRP.
\end{abstract}

\section{Introduction}

Composites are materials consisting of a mixture of components present as separate phases. They are created for engineering applications to combine the desired qualities of its individual components. Carbon fiber reinforced polymers (CFRP) are carbon fiber composites (CFC) consisting of carbon fibers embedded in a polymer matrix, typically a resin. The most common production technique is to build CFRP as laminates. These laminates are stacked from unidirectional or woven carbon fiber plies preimpregnated with resin, which are commonly referred to as prepreg. The laminate is stacked in a mold to form the desired part geometry, vacuum-bagged, and cured in an autoclave.

The motivation to use CFRP is found in their mechanical properties. While Young's modulus $E$ of CFRP is lower than that of many metals, the density of CFRP is much lower. Young's modulus per material density of CFRP is much higher than that of metals; for example, the specific tensile modulus of steel is about $26 \mathrm{GPa} /\left(\mathrm{g} / \mathrm{cm}^{3}\right)$, while for unidirectional CFRP (UD-CFRP) values $>100 \mathrm{GPa} /\left(\mathrm{g} / \mathrm{cm}^{3}\right)$ can be easily achieved in fiber direction. This makes CFRP a suitable material for lightweight construction.

Carbon fibers are electric conductors, while the matrix is almost exclusively nonconductive. The electromagnetic properties of CFRP laminates are in general anisotropic and depend on fiber and matrix materials, ply weave, orientation of the layers in the laminate, and frequency. In the past, due to their application in avionics and aeronautics, the research focus was on the electromagnetic shielding properties of carbon fiber composites $[1,2]$. For antenna design the electrical conductivity, permittivity, and magnetic permeability of the materials in the vicinity of the antenna are of interest.

Measurements of radio-frequency electromagnetic properties are performed by inserting a material sample (material under test, MUT) inside a well understood system, such as a waveguide $[3,4]$ and coaxial cable, or between horn antennas [5]. The electrical conductivity and permittivity transverse and parallel to UD-CFRP and with different fiber volume fractions were measured with waveguides in [6]; values are given in a large frequency range up to $10 \mathrm{GHz}$. The conductivity of CFRP is much higher than that of carbon-black 
or graphite particulate composites [7]; conductivity of UDCFRP in and perpendicular to fiber direction differs by a factor of $10^{5}$. Horn antenna measurements have shown that the conductivity of CFC with unidirectional fibers increases with frequency if the electrical field is perpendicular to the fibers but is flat with the field parallel to the fiber direction [8]. Waveguide measurements of electrical conductivity and permittivity with the Nicolson-Ross-Weir (NRW) method and different ply orientation in the range of $8 \mathrm{GHz}$ to $12 \mathrm{GHz}$ have been conducted in [9], where they also provide measurements of CFRP slot antennas. CFRP are diamagnetic; the magnetic permeability of unidirectional carbon fiber polymer laminates was measured with horn antennas and waveguides in [10]. In most investigations only CFRP made with unidirectional fiber direction, and plies which are all oriented in the same direction, are considered. UD-CFRP are more interesting from a theoretical viewpoint as the material anisotropy is more pronounced and the material is easier to model. In applications however, woven fabrics are often used to compensate the small $E$-module and/or low electric conductivity perpendicular to fiber direction.

Modeling approaches for the electrical properties of CFC have been proposed in $[11,12]$ in addition to simple law of mixture models used in $[1,13]$.

CFRP are used in a variety of antenna applications. The whole antenna can be built from CFRP. Measurements of braided CFRP patch antennas are compared to law of mixture and geometry based simulations in [14]. The performance of bow-tie antennas with unidirectional and braided CFRP is measured in [15]. Various monopole antennas made from CFRP and carbon nanotubes are investigated in $[16,17]$. Slotted waveguide antennas manufactured from CFRP are investigated in [18]. This type of antenna is especially relevant in aeronautical applications. Load bearing structures are formed from CFRP and the geometry obtained for mechanical stability is close to the geometry of rectangular waveguides. CFRP bearers can be used as rectangular waveguides and slots can be cut into them to build rectangular waveguide antennas [19]. Several elements can be combined into an antenna array, the slotted waveguide antenna stiffened structure [20].

CFRP are used for lightweight construction of reflectors, mostly in large parabolic dishes [21] or space applications [22]. Measurements in [23] show that CFRP is applicable as reflector material for millimeter-wave antennas at $100 \mathrm{GHz}$. Antenna gain with a reflector made from woven CFRP is close to the gain with a chrome plated reflector. It should be noted that CFRP cannot be used in some antenna applications as they are a source of intermodulation products [24].

CFRP are used as antenna ground plane material. In specialized applications the high anisotropy of UD-CFRP can be utilized. A mechanically reconfigurable antenna with an anisotropic CFRP ground plane is presented in [25]. Surface currents on the ground plane can flow in fiber direction, while they are blocked perpendicular to fiber direction due to the low conductivity of CFRP. This mechanism acts as a mode filter for a patch antenna which is rotated against the CFRP ground plane. In general, however, the conductivity of the antenna ground plane should be isotropic.
A typical use case as ground plane is when antennas are mounted on large CFRP structures such as an aircraft fuselage or a car chassis. The influence of the ground plane material on the antennas should be small to allow antenna design independent of composite design. To achieve this, CFRP with near anisotropic conductivity are preferred, such that electric currents are not obstructed. This is especially the case in automotive antenna design, where antenna modules are used on different types of vehicle and are required to function on the CFRP roof of electric cars as well as on steel roofs. An automotive roof mounted antenna module (shark-fin) is measured on a CFRP car roof in [26]. An antenna cavity for integration into CFRP sheets, such as aircraft skin panels or car chassis, is proposed and prototyped in [27]. In vehicular applications the antenna cavity can be manufactured as part of a carbon fiber reinforced car roof as is described in [28].

A CFRP material with carbon fiber shreds in random alignment as its top layer is proposed for antenna applications and manufactured. Fiber shreds can be obtained from recycled CFRP, resulting in a sustainable material. Due to the skin effect, it is sufficient to design the top layer of the laminate for antenna applications in the gigahertz range; the other plies can be chosen independently to meet the mechanical requirements of the composite. The material is described in Section 2. Its electromagnetic properties are measured with the NRW method in a rectangular waveguide and compared to a CFRP with a $2 / 2$ twill weave in Section 3.1. Material measurements are performed in the frequency band from $4 \mathrm{GHz}$ to $6 \mathrm{GHz}$, which includes the frequency band from $5.85 \mathrm{GHz}$ to $5.925 \mathrm{GHz}$, that is reserved for dedicated short range communication (DSRC) in intelligent transportation systems (ITS), IEEE 802.11p. The influence of the proposed CFRP as ground plane material is measured with several monopole antennas in Section 4. The proposed CFRP is measured as ground plane for a wire monopole antenna for the $5.9 \mathrm{GHz}$ DSRC band and with broadband conical monopole antennas in a frequency range from $1 \mathrm{GHz}$ to $10 \mathrm{GHz}$.

\section{CFRP for Antenna Applications}

In general, the influence of a CFRP ground plane on the antenna should be small. For antenna applications CFC are preferred over graphite or carbon-black particulate composites due to their larger conductivity in fiber direction [7]. Woven carbon fiber plies are used to achieve a more isotropic conductivity than unidirectional plies [8]. However, the geometry of a chosen weave might result in unwanted resonances. A straightforward method to diminish the anisotropic conductivity of CFRP is to superimpose an isotropic metallic layer onto the CFRP, include it in the laminate during production, or metalize the CFRP surface. In many applications this is not possible because of the different thermal expansion coefficients of the materials or simply because of too high costs.

It is proposed to use a CFRP with fiber shreds in random alignment in antenna applications. Random fiber alignment results in a composite with a more isotropic conductivity than UD-CFRP and does not have characteristic geometries 


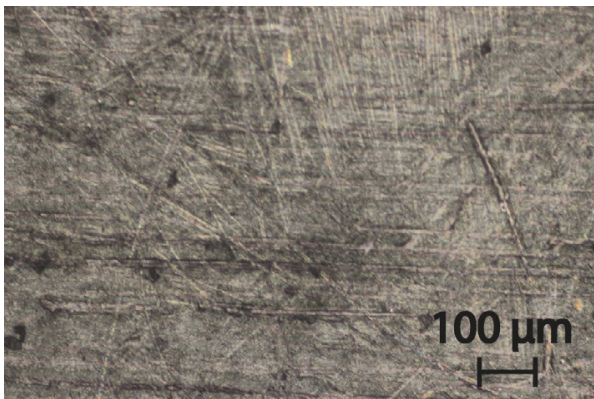

(a)

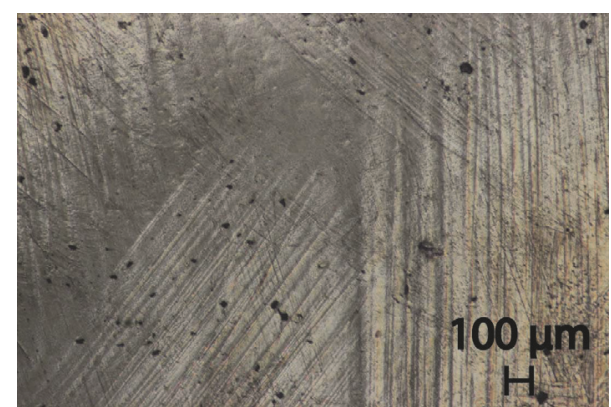

(b)

FIGURE 1: Microscopic photographs of (a) the proposed CFRP with fiber shreds in random alignment on top and (b) the twill-weave CFRP reference material. The unidirectional filaments are visible underneath the fiber shreds as horizontal lines.

associated with woven carbon plies. The quasi-random fiber alignment is easy in production, as the fiber shreds can be dropped or blown onto the mold or laminate. Fiber shreds can be obtained from CFRP recycling processes [29]. Due to the skin effect it is sufficient to design the top layer of the laminate for antenna applications; the remaining plies can be designed to meet mechanical requirements.

A microscopic photograph of a material sample taken from a CFRP with unidirectional plies and fiber shreds in random alignment on top is depicted in Figure 1(a). The unidirectional filaments under the fiber shreds are visible as horizontal lines in the photograph. In production the fiber shreds are of course not aligned completely random; an example is depicted on the top border of Figure 1(a), where a bundle of carbon fiber shreds is aligned facing downwards. The shred-CFRP has a total thickness of $2.26 \mathrm{~mm}$. The material is compared to a 2/2 twill-weave CFRP depicted in Figure 1(b). The twill-CFRP has a thickness of $0.9 \mathrm{~mm}$, consists of 5 layers of 2/2 twill weave stacked as [4 $\left.\begin{array}{lllll}45 & 90 & 45 & 90 & 45\end{array}\right]$, and has 1000 fiber filaments per roving.

\section{Material Measurements}

3.1. NRW Method. The electromagnetic properties (conductivity, permittivity, and permeability) of the proposed CFRP with fiber snippets on top are measured at radio frequencies. Results are compared to measurements of a CFRP with a twill weave as described in Section 2. Values for UD-CFRP are already well known in literature. A method developed by Nicolson-Ross-Weir (NRW) [30, 31] enables the characterization of material samples inside a waveguide by calculating the electrical characteristics from measured scattering parameters ( $S$-parameters). Rectangular material samples are cut from the CFRP and placed in a fixture inside a rectangular waveguide that operates in its dominant $\mathrm{TE}_{10}$ mode. The waveguide is connected to a vector network analyzer and $S$-parameters are measured. The NRW method is then used to calculate the electrical and magnetic material parameters from the $S$-parameters obtained by waveguide measurements. The formulas for $S$-parameter conversion, where the complex material parameters $\epsilon_{r}, \mu_{r}$ and the conductivity $\sigma$ are extracted, can be found in $[5,32]$. The position of the MUT inside the fixture is considered according to
[32], where $L_{1}$ and $L_{2}$ are the distance from the MUT to the calibration plane of port 1 and port 2 inside the waveguide, respectively:

$$
\begin{aligned}
R_{i} & =e^{-\gamma_{0} L_{i}}, \quad i \in\{1,2\}, \\
S_{11}^{C} & =\frac{S_{11}}{R_{1}^{2}}, \\
S_{21}^{C} & =\frac{S_{21}}{R_{1} R_{2}} .
\end{aligned}
$$

The scattering parameters $S_{11}^{C}$ and $S_{21}^{C}$ are the basis for the Nicolson-Ross-Weir (NRW) equations:

$$
\begin{aligned}
\Gamma & =X \pm \sqrt{X^{2}-1}, \\
X & =\frac{\left(S_{11}^{C}\right)^{2}-\left(S_{21}^{C}\right)^{2}+1}{2 S_{11}^{C}}, \\
\frac{1}{\Lambda^{2}} & =-\left(\frac{1}{2 \pi d} \ln \left(\frac{1}{P}\right)\right)^{2}, \\
P & =\frac{S_{11}^{C}+S_{21}^{C}-\Gamma}{1-\left(S_{11}^{C}+S_{21}^{C}\right) \Gamma},
\end{aligned}
$$

with the thickness of the MUT $d$ and propagation factor $P$ and with the sign in (2) to be chosen such that the reflection coefficient is $|\Gamma| \leq 1 \cdot \operatorname{Re}\{1 / \Lambda\}=1 / \lambda_{g}$ with the transmission line guide wavelength $\lambda_{g}$. Note that the logarithm in (4) is ambiguous by $2 \pi n, n \in \mathbb{N}_{0}$, as $P$ is complex in general. The ambiguity problem is resolved by choosing thin samples of thickness $d<\lambda / 2$ [32], resulting in $n=0$. This is the case for the presented CFRP measurements in the low gigahertz range, as these composites are commonly manufactured as (thin) laminates. To check whether the $n=0$ assumption is valid, the method based on group delay from [31] was also implemented. For this method the group delay is calculated for each frequency as $\tau_{g n}$ and compared to the group delay 
$\tau_{g}$, which is based on the slope of the propagation factor

$$
\begin{aligned}
\tau_{g n} & =d \cdot \frac{\mathrm{d}}{\mathrm{d} f}\left[\left(\frac{\epsilon_{r} \mu_{r}}{\lambda_{0}^{2}}-\frac{1}{\lambda_{c}^{2}}\right)_{n}^{1 / 2}\right], \\
\tau_{g} & =\frac{1}{2 \pi} \frac{\mathrm{d}(-\phi)}{\mathrm{d} f},
\end{aligned}
$$

with $\phi=\arg (P)$. The derivatives in (6) are approximated by finite differences between measured frequency bins. The correct root $n=k$ is then chosen such that $\tau_{g k}-\tau_{g} \approx 0$. The group delay method also resulted in $n=0$ in the frequency band of the fundamental mode of the waveguide.

The complex magnetic permeability and electric permittivity are then obtained as

$$
\begin{aligned}
& \mu_{r}=\mu_{r}^{\prime}-j \mu_{r}^{\prime \prime}=\frac{1+\Gamma}{\Lambda(1-\Gamma) \sqrt{1 / \lambda_{0}^{2}-1 / \lambda_{c}^{2}}}, \\
& \epsilon_{r}=\epsilon_{r}^{\prime}-j \epsilon_{r}^{\prime \prime}=\frac{\lambda_{0}^{2}}{\mu_{r}}\left(\frac{1}{\lambda_{c}^{2}}+\frac{1}{\Lambda^{2}}\right) .
\end{aligned}
$$

In (7) $\lambda_{0}$ denotes the wavelength in free space at measurement frequency and $\lambda_{c}$ the cut-off frequency of the waveguide.

The surface conductivity of the material is derived from

$$
\sigma=\frac{4 \pi \mu_{0} f\left(1-\left|S_{11}\right|^{2}\right)^{2}}{Z_{0}^{2}\left(\left(1+\left|S_{11}\right|^{2}\right)-\sqrt{-\left|S_{11}\right|^{4}+6\left|S_{11}\right|^{2}-1}\right)^{2}},
$$

with the magnetic constant $\mu_{0}$, frequency $f$, and the free space impedance $Z_{0}$; see [9].

3.2. Measurement Setup. The waveguide WR187 has a dimension of $a=47.5 \mathrm{~mm} \times b=22.1 \mathrm{~mm}$. The cut-off frequency of the $\mathrm{TE}_{10}$ mode is $f_{c}=c_{0} / 2 a \approx 3.16 \mathrm{GHz}$ and the nominal frequency range is $3.94-5.99 \mathrm{GHz}$.

Samples are cut from the CFRP materials for a selected set of discrete orientations and grinded to fit into a waveguide fixture. The waveguide was cleaned with alcohol and calibrated using a through-reflect-match (TRM) calibration. The fixture with the sample is then fastened in the middle of the waveguide, the $S$-parameters are measured with a network analyzer (R\&S ZVA24), and the electrical properties are calculated in a Matlab script as presented in Section 3.1. The disassembled measurement setup is depicted in Figure 2.

To measure the angular dependency of the materials, the samples are cut in various orientations $\varphi$. Twill-CFRP sample orientations range from $0^{\circ}$ to $90^{\circ}$ in steps of $10^{\circ}$ and shredCFRP samples are cut from $0^{\circ}$ to $110^{\circ}$ in $5^{\circ}$ steps, where $\varphi$ is the deviation from an arbitrary defined direction on the material surface. Three additional samples with $\varphi=0^{\circ}$ are cut from different positions of shred-CFRP to assess the impact of cutting precision and material inhomogeneity.

There are several known sources of inaccuracies when measuring material samples inside a waveguide. The sample might be displaced inadvertently from the calibration plane.

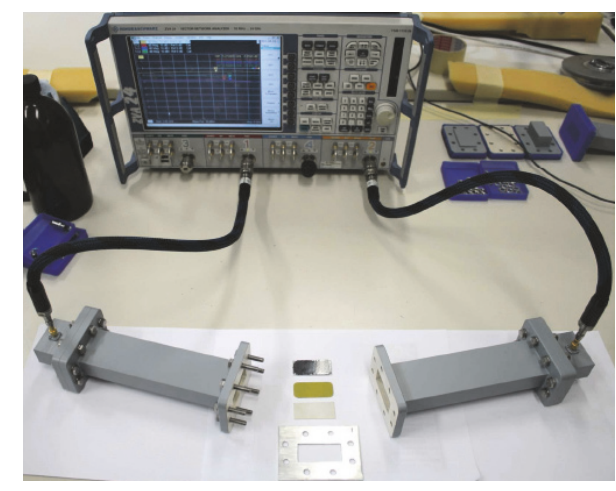

FIGURE 2: Measurement setup consisting of WR187 waveguides, sample fixture, and R\&S ZVA24 network analyzer.

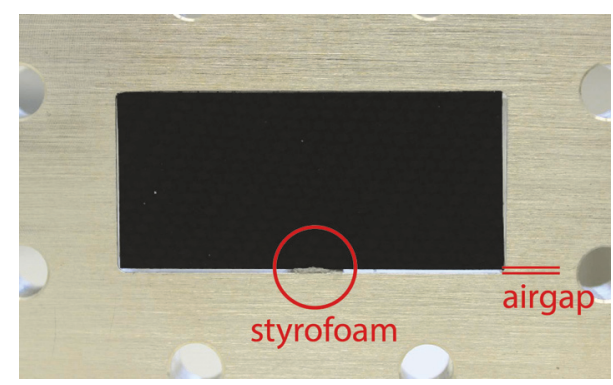

FIGURE 3: Attachment of a sample with air-gap in the waveguide fixture by clamping a piece of styrofoam into the air-gap, on the example of a twill-CFRP sample with an alignment of $60^{\circ}$.

It may tilt and, due to imprecise manufacturing, air-gaps might appear between sample and the waveguide walls. To mitigate these sources of inaccuracies, a small piece of styrofoam is clamped between sample and fixture when necessary, as shown in Figure 3.

3.3. Measurement Results. Results for the permittivity, permeability, and conductivity of shred-CFRP are presented in Figures 4(a), 5(a), and 6(a), respectively and results for twill-CFRP are depicted in Figures 4(b), 5(b), and 6(b), respectively. The orientation dependent results are shown for $4 \mathrm{GHz}, 5 \mathrm{GHz}$, and $5.9 \mathrm{GHz}$ (ITS G5). Measured values for different sample orientations are connected by straight lines only for visual guidance.

The permittivity of the two CFRP is high when compared to [6], where $\epsilon_{r}$ for unidirectional fibers in epoxy was around 1 for electrical field parallel to fiber alignment and ranged from 5 to 20 for transverse fields, and [9], where $\epsilon_{r}$ was approximately 30 for both unidirectional and $\left[\begin{array}{llll}0 & 45 & 90 & -45\end{array}\right]$ fiber alignment.

Twill-CFRP shows strong dependency of $\mu_{r}$ on the angle, while all measured shred-CFRP samples have low $\mu_{r}$ independent of their alignment. The diamagnetic behavior of CFRP (Figure 5) is in accordance with [10], where the real part of $\mu_{r}$ varies between 0 and 1 dependent on orientation of a UD-CFRP.

The conductivity anisotropy of the shred-CFRP (and the twill-CFRP) is significantly lower than that of UD-CFRP. The 

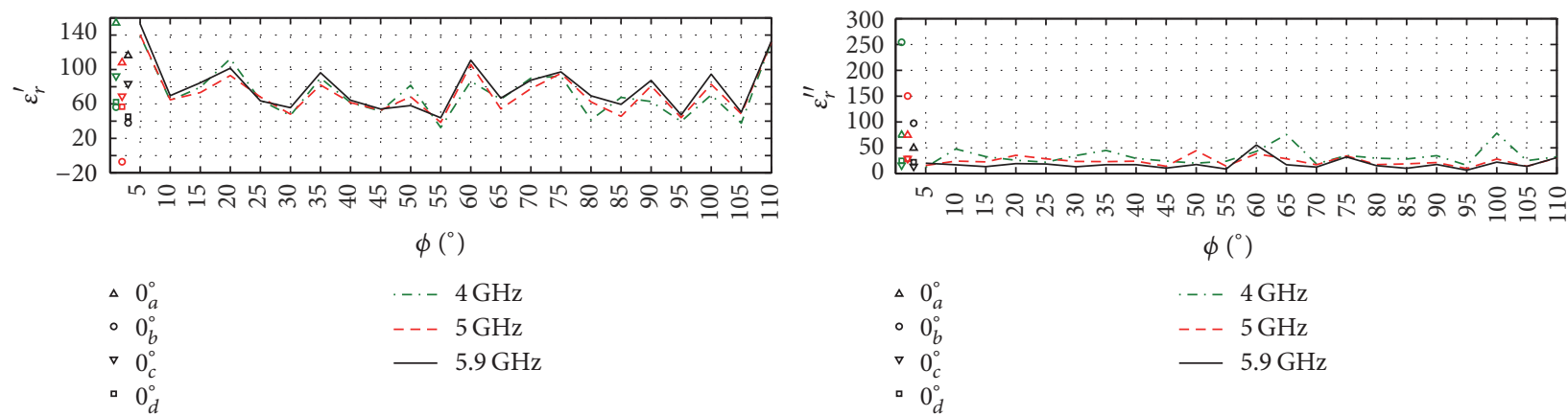

(a) Permittivity, shred-CFRP
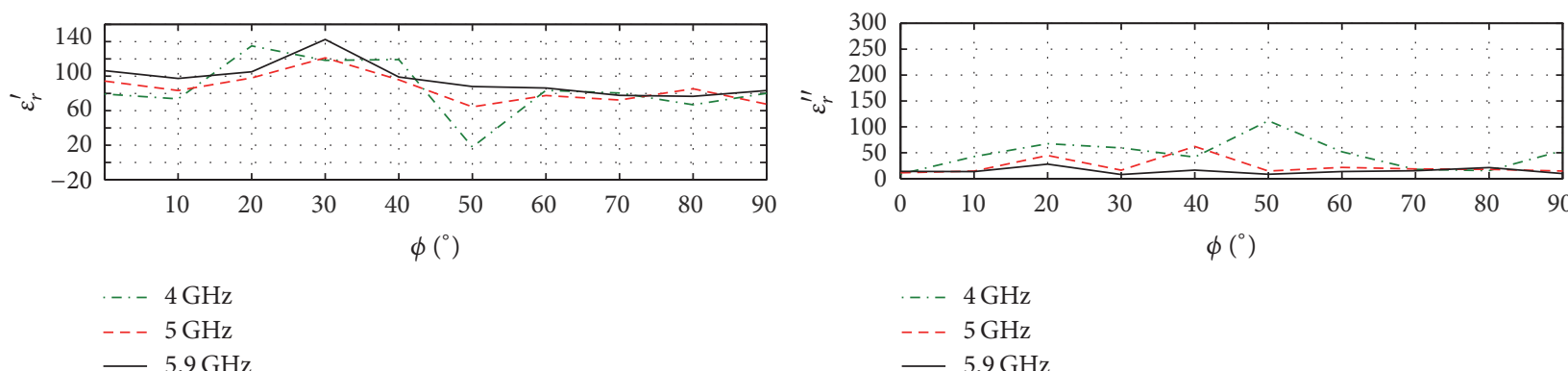

(b) Permittivity, twill-CFRP

FIgURE 4: Permittivity of (a) shred-CFRP and (b) twill-CFRP dependent on the orientation of the cut sample.

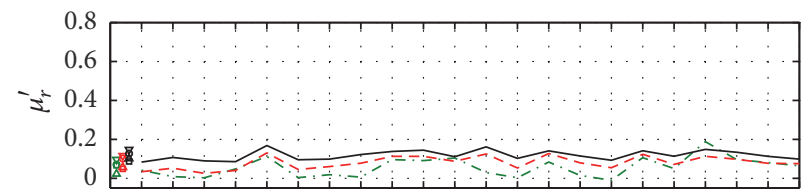

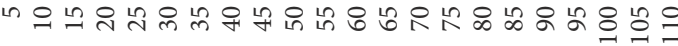
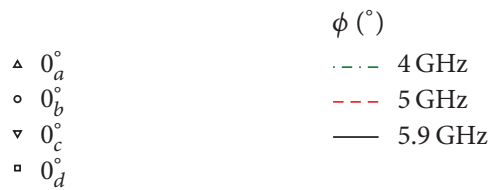

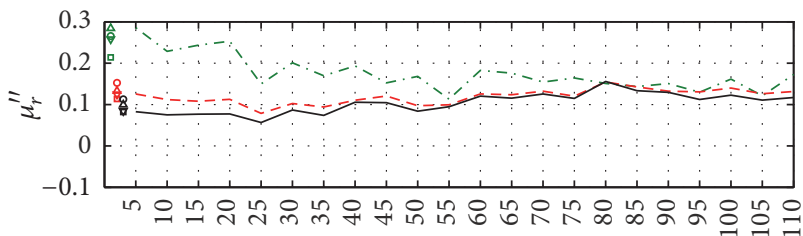

$\phi\left(^{\circ}\right)$

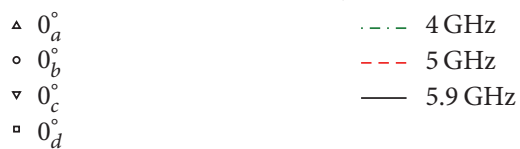

(a) Permeability, shred-CFRP
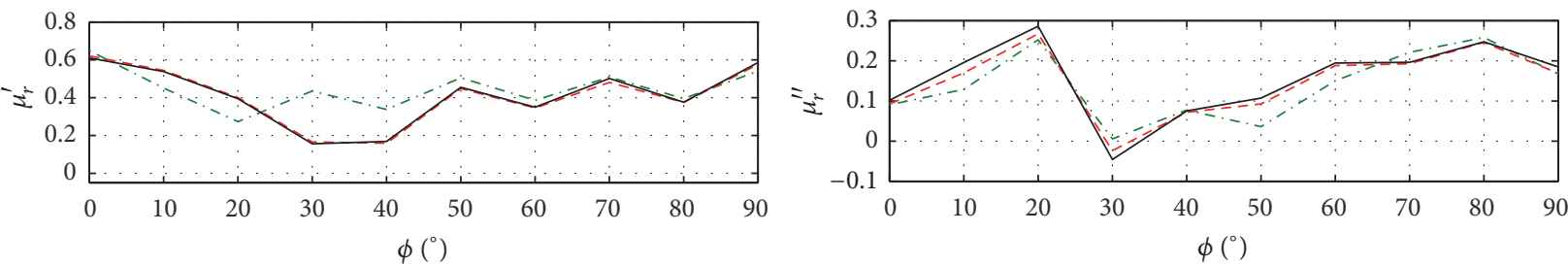

-.- $4 \mathrm{GHz}$

-. $-4 \mathrm{GHz}$

- - $5 \mathrm{GHz}$

- - $5 \mathrm{GHz}$

$-5.9 \mathrm{GHz}$

$-5.9 \mathrm{GHz}$

(b) Permeability, twill-CFRP

FIGURE 5: Permeability of (a) shred-CFRP and (b) twill-CFRP dependent on the orientation of the cut sample.

conductivity of shred-CFRP is about $10^{4} \mathrm{~S} / \mathrm{m}$. Conductivity varies by a factor of 10 depending on the angle for a given frequency. Reference [7] reports a factor of $10^{5}$ between conductivity in fiber direction $\left(\approx 10^{2} \mathrm{~S} / \mathrm{cm}\right)$ and that perpendicular to fiber direction $\left(\approx 10^{-3} \mathrm{~S} / \mathrm{cm}\right)$. Reference [6] reports a longitudinal conductivity of $\approx 400 \mathrm{~S} / \mathrm{cm}$ with a sharp decline towards zero between $10^{8} \mathrm{~Hz}$ and $10^{10} \mathrm{~Hz}$ and transverse conductivity around $10^{-2} \mathrm{~S} / \mathrm{cm}$. For a CFRP with unidirectional plies that are stacked as $\left[\begin{array}{llll}0 & 45 & 90 & -45\end{array}\right]_{2 s}$ conductivity varies between $5000 \mathrm{~S} / \mathrm{m}$ (parallel) and $1000 \mathrm{~S} / \mathrm{cm}$ 


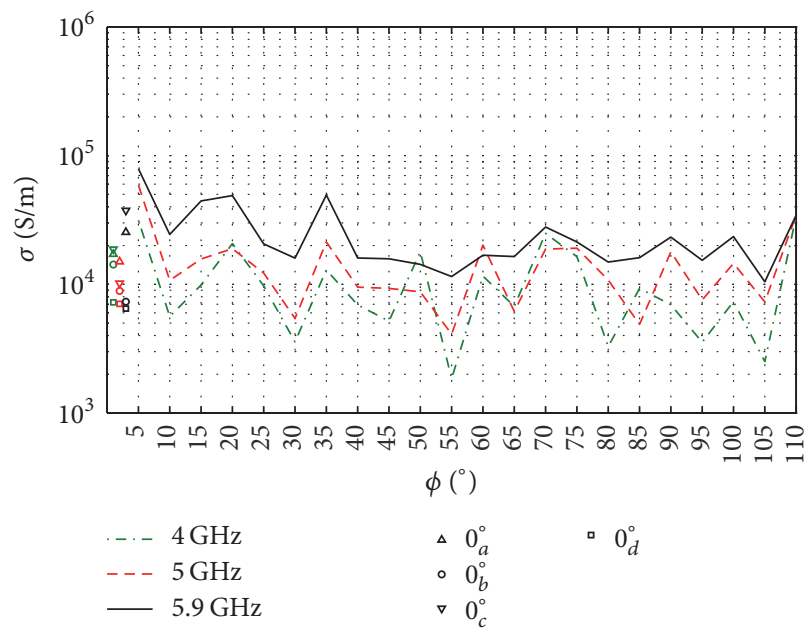

(a) Conductivity, shred-CFRP

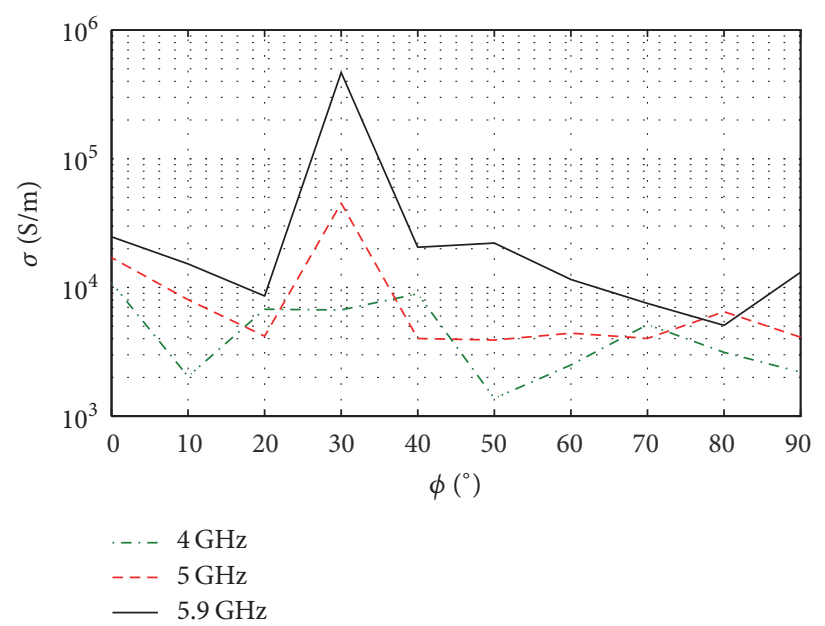

(b) Conductivity, twill-CFRP

FIgURE 6: Conductivity of (a) shred-CFRP and (b) twill-CFRP dependent on the orientation of the cut sample.

(perpendicular) [9] (8-12 GHz). The conductivity of the shred-CFRP is slightly higher than that of the twill-CFRP.

Note that the NRW estimates allow slightly negative values for the magnetic permeability, although such negative values are not compatible with passivity of the material. These stem from measurement inaccuracies together with the numerical sensitivity of the NRW method which does not enforce passivity of the material. Negative parameter estimates become apparent when the permeability is close to zero, as depicted in Figure 5(a). The $\epsilon_{r}^{\prime}$ value of the $0^{\circ} \mathrm{b}$ shred-CFRP sample in Figure 4(a) and $\mu_{r}^{\prime \prime}$ of the $30^{\circ}$ twillCFRP sample in Figure 5(b) serve as indicators for the overall accuracy of the parameter estimates.

To investigate the homogeneity of the shred-CFRP, four samples with the same orientation were cut from different regions of the material. They are referred to as $0_{a}^{\circ}, 0_{b}^{\circ}, 0_{c}^{\circ}$, and $0_{d}^{\circ}$. The conductivity measurements of these four samples dependent on frequency are depicted in Figure 7. Although the four samples in Figure 7 have the same orientation, their frequency behavior is different. The conductivity of samples $0_{a}^{\circ}$ and $0_{c}^{\circ}$ increases with increasing frequency, the conductivity of sample $0_{b}^{\circ}$ decreases with frequency, and the conductivity of sample $0_{d}^{\circ}$ stays approximately the same over the investigated frequency range. Additionally, the spread of values for the $0^{\circ}$ samples resembles the value range of the other samples in Figures 4(a), 5(a), and 6(a). The conclusion must be that the material is either inhomogeneous or that the measurements are not accurate enough to measure an angular dependency of the radio-frequency properties of the proposed CFRP. The microscopic photograph depicted in Figure 1(a) suggests that the proposed CFRP is not homogenous, as fibers were not uniformly distributed during production and strands of fibers with same alignment are still present on the surface. However, it is shown in Section 4 that the local inhomogeneity and anisotropy of the CFRP ground plane with fiber shreds have no relevant influence on monopole antennas.

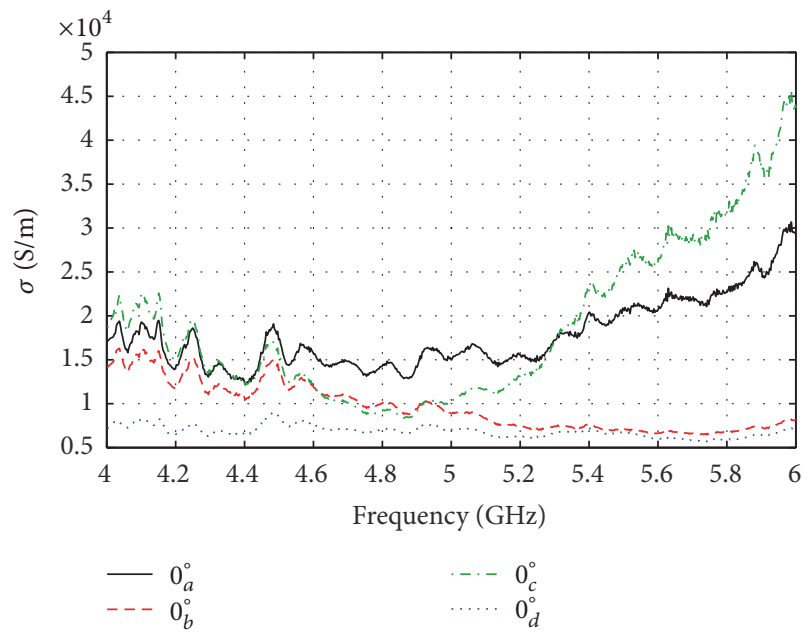

FIGURE 7: Conductivity of four shred-CFRP samples with the same alignment $\left(0^{\circ}\right)$, cut from different positions of the material.

At $5.9 \mathrm{GHz}$ the fiber shreds of shred-CFRP lead to a smaller spread of conductivity values than a woven structure like that of twill-CFRP. The conductivity of shred-CFRP varies only between $10^{4} \mathrm{~S} / \mathrm{m}$ and $8 \cdot 10^{4} \mathrm{~S} / \mathrm{m}$ at $5.9 \mathrm{GHz}$. When building monopole antennas with a shred-CFRP ground plane, this change leads to a negligible influence on antenna radiation patterns as presented in Section 4.1. Broadband measurements of conical monopole antennas in Section 4.2 show that shred-CFRP is an excellent ground plane material with results close to aluminum.

\section{Antennas with CFRP Ground Planes}

To the best of the authors' knowledge, the first measurement of the influence of CFRP as a ground plane material of a monopole antenna was performed in [33] for $1 \mathrm{GHz}$. 


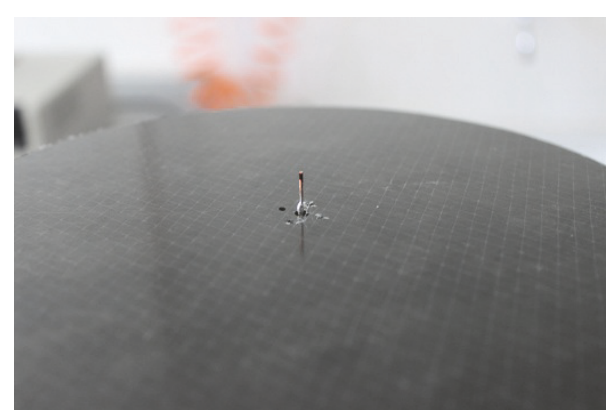

Figure 8: Monopole antenna for $5.9 \mathrm{GHz}$ on a circular shred-CFRP ground plane.

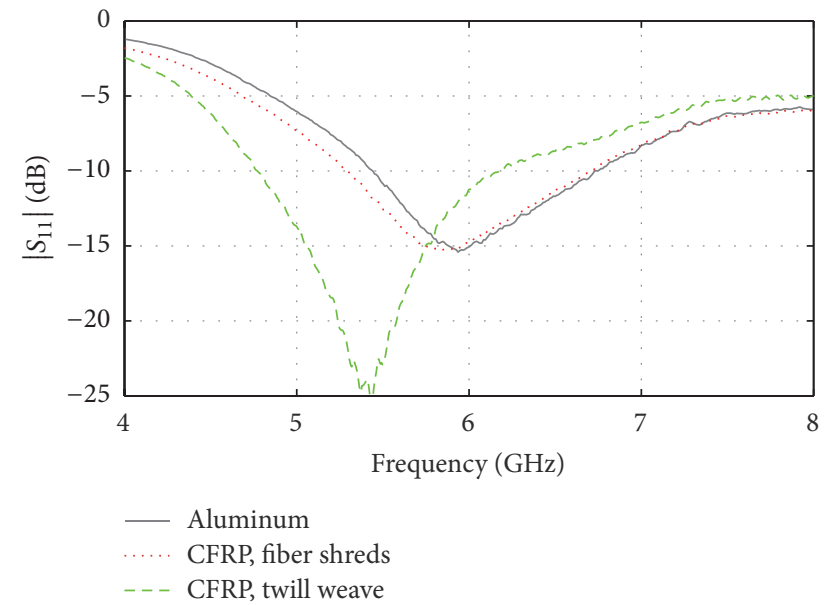

FIgURE 9: Measured $S$-parameters of the wire monopole antennas on different ground planes (reprinted with permission from [34]; (C)2014 IEEE).

The influence of the composite anisotropy was undetectable within the measurement accuracy. However, no detailed description of the investigated CFRP was given. Monopole antennas are investigated, because they are well known antennas and are already used in various applications where large CFRP ground planes are available. Performance of shred-CFRP is expected to be similar for other antenna types.

4.1. Wire Monopole Antenna for $5.9 \mathrm{GHz}$. A wire monopole antenna for DSRC at $5.9 \mathrm{GHz}$ is measured on CFRP ground planes [34]. The monopole antenna is a metal wire cut to a length of about $\lambda / 4$ such that it is resonant at $5.9 \mathrm{GHz}$. The wire is soldered to the inner connector of a subminiature version A (SMA) flange, which is screwed to threaded holes in the ground plane. The wire monopole antenna is measured on circular ground planes with $195 \mathrm{~mm}$ diameters. The wire monopole antenna on a circular ground plane from shredCFRP is depicted in Figure 8. The shred-CFRP and twillCFRP are the same as in Section 3.

To measure the influence of a CFRP ground plane on a narrowband antenna, the monopole wire is trimmed such that it is resonant at $5.9 \mathrm{GHz}$ on an aluminum ground plane. The measured $S$-parameters are depicted in Figure 9. The resonance frequency of the antenna is shifted to about

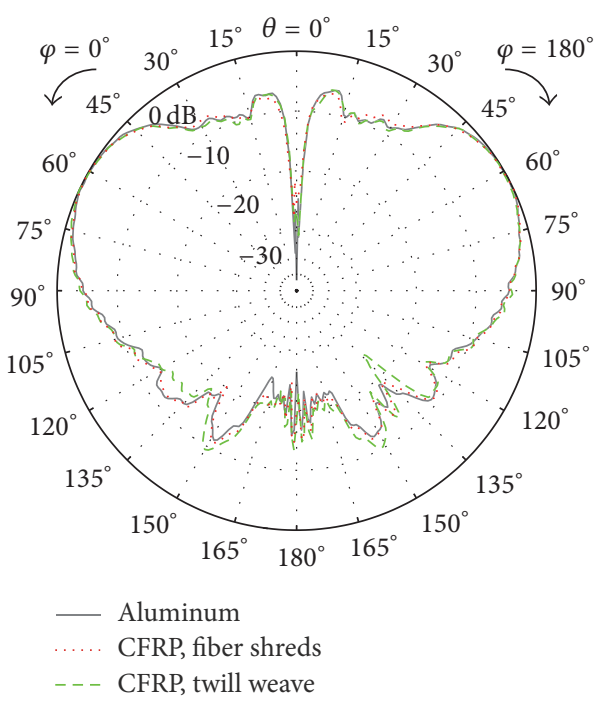

FIGURE 10: Monopole antenna for $5.9 \mathrm{GHz}$ on a circular ground plane. Vertical cut of the normalized measured gain pattern for azimuth $\varphi=0^{\circ}$ (reprinted with permission from [34]; (C2014 IEEE).

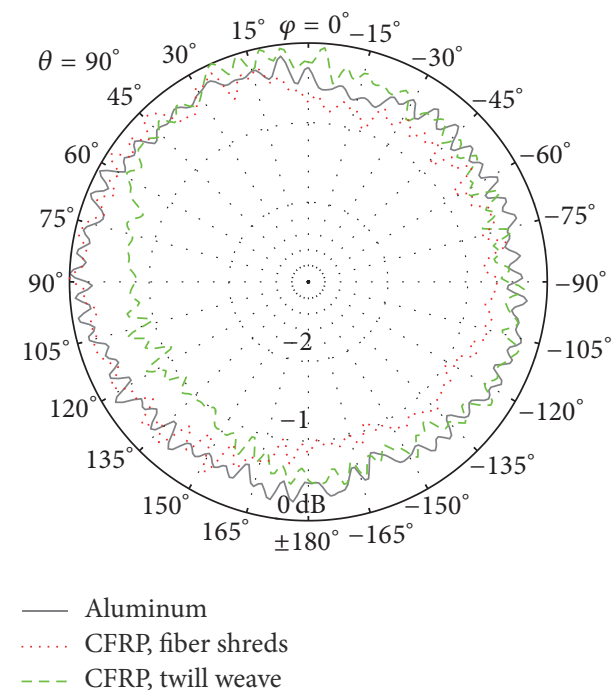

FIgURE 11: Monopole antenna for $5.9 \mathrm{GHz}$ on a circular ground plane. Horizontal cut of the normalized measured gain pattern for polar angel $\theta=90^{\circ}$ (reprinted with permission from [34]; (C2014 IEEE).

$5.4 \mathrm{GHz}$ when placed on the twill-CFRP. The length of the wire was not adjusted, as the return loss at $5.9 \mathrm{GHz}$ is still better than $10 \mathrm{~dB}$. In a practical application the dimensions will be adjusted, such that the antenna is resonant at the desired frequency.

Gain pattern measurements are performed inside the institute's anechoic chamber. The vertical cuts of the gain patterns at azimuth $\varphi=0^{\circ}$ are shown in Figure 10. The horizontal cuts of the measured gain patterns are depicted in Figure 11. The patterns are normalized. Vertical cuts of the patterns show no significant deviation; no additional zeros or notches are introduced by the shred-CFRP. The influence 


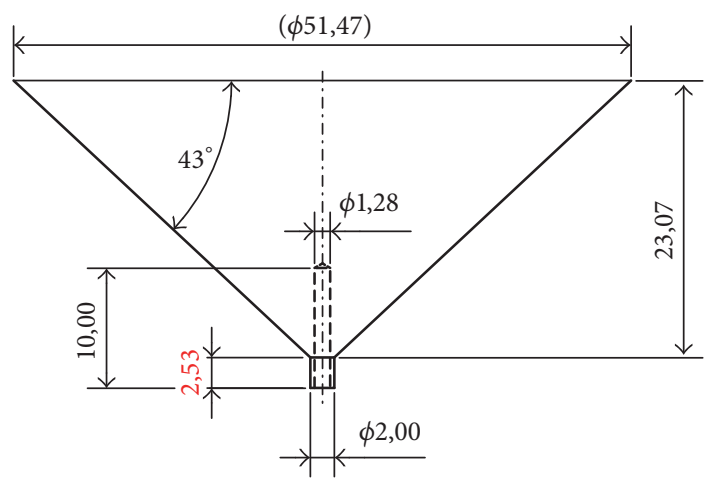

FIGURE 12: Cone dimensions of the broadband monopole antenna. The cylindrical stub on the bottom (red) is designed to fit over the inner conductor of an SMA flange, its length is adjusted to the thickness of the ground plane. All dimensions are in millimeter (reprinted with permission from [35]; (C2017 IEEE).

of the shred-CFRP on the antenna's radiation pattern in the horizontal plane is smaller than $1 \mathrm{~dB}$ and can be neglected in most applications. Radiation efficiency on the shred-CFRP ground plane is reduced by $23 \%(1.14 \mathrm{~dB})$ compared to the efficiency on an aluminum ground plane in [34].

4.2. Conical Monopole Antenna on CFRP Ground Planes. Conical monopole antennas turned from brass are used to measure the influence of CFRP as ground plane material on antennas from $1 \mathrm{GHz}$ to $10 \mathrm{GHz}$ [35]. Cone dimensions are depicted in Figure 12. The cones have cylindrical stubs at the tip that fit tightly over the inner conductor of a coaxial SMA flange. As the ground planes have different thickness, several cones are manufactured with different lengths of the stubs, such that the tip of the cone is always positioned at the surface level of the material. The SMA flanges are screwed to threaded holes drilled into the ground planes. The antennas are measured on circular ground planes manufactured from shred-CFRP, twill-weave CFRP, UD-CFRP, and aluminum. All ground planes have a diameter of $300 \mathrm{~mm}$. As threading the thin twill-CFRP ground plane in Section 4.1 was challenging, a thicker twill-CFRP was used as reference material for the measurements of the conical monopole antennas. The twill-CFRP is a $1.6 \mathrm{~mm}$ thick $2 / 2$ twill weave stacked as [0 90] that is commercially available from CG-TEC and has a fiber volume fraction of $63 \%$ according to manufacturer.

Measured S-parameters are depicted in Figure 13. Return loss is better than $10 \mathrm{~dB}$ between $2 \mathrm{GHz}$ and $10 \mathrm{GHz}$ for all ground plane materials. The return loss with the UD-CFRP is a bit reduced but still better than $10 \mathrm{~dB}$.

Gain patterns are again measured in the institute's anechoic chamber (Figure 14). Gain patterns presented in this section are not normalized and are given according to the IEEE gain definition based on accepted power, in order to emphasize the large influence of UD-CFRP in comparison to the shred-CFRP and twill-CFRP. Vertical cuts of the measured gain patterns are depicted in Figure 15. Cuts for azimuthal angle $\varphi=0^{\circ}$ and $\varphi=90^{\circ}$ are shown on the left and right side, respectively. For the UD-CFRP $\varphi=0^{\circ}$

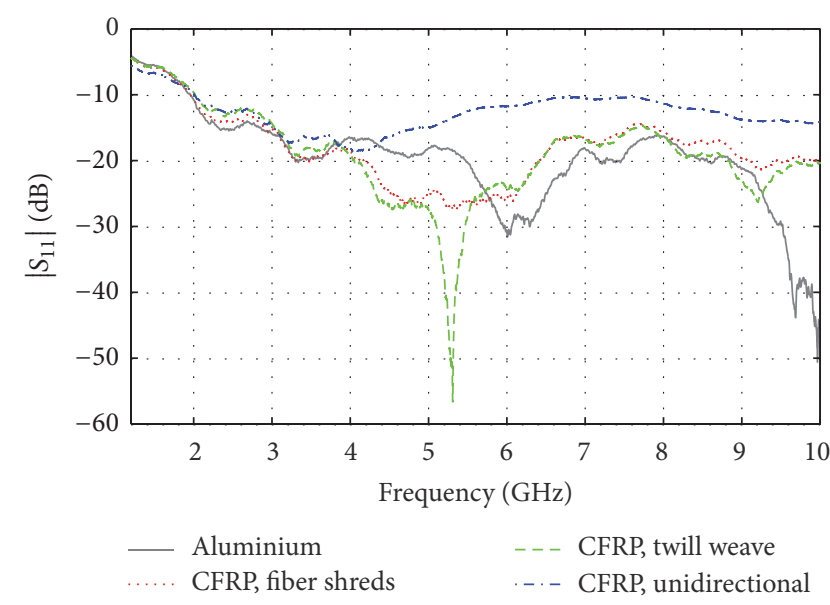

FIGURE 13: Measured $S$-parameters of the conical monopole antenna on different ground plane materials (reprinted with permission from [35]; (2017 IEEE).

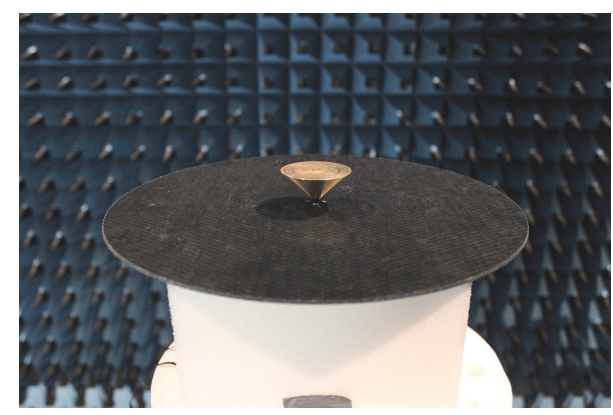

FIGURE 14: Conical monopole antenna on the shred-CFRP ground plane. The antenna is placed on a Rohacell column on an azimuth rotary stage inside the university's anechoic chamber.

corresponds with fiber direction and $\varphi=90^{\circ}$ is perpendicular to fiber direction. The CFRP with fiber shreds and the twillweave CFRP perform similar to aluminum in the whole frequency range. With the UD-CFRP antenna gain in fiber direction $\left(\varphi=0^{\circ}\right)$ is $1-4 \mathrm{~dB}$ lower than on aluminum. The shape of the gain pattern in fiber direction remains widely unchanged, but radiation perpendicular to fiber direction is greatly diminished for the UD-CFRP and the gain pattern is changed, especially for radiation in the horizontal plane $\theta \approx$ $90^{\circ}$. For the conical monopole antenna radiation efficiency on shred-CFRP is measured close to that of aluminum in the frequency range from $1 \mathrm{GHz}$ to $10 \mathrm{GHz}$, about $0.5 \mathrm{~dB}$ lower at $5.9 \mathrm{GHz}$ [35].

The measurements show that using a UD-CFRP has a huge influence on antennas. The anisotropic conductivity of UD-CFRP obstructs surface currents on the ground plane leading to reduced gain and changed radiation pattern perpendicular to fiber direction. Although the anisotropy may be useful [25], a good isotropic conductor is most desirable as antenna ground plane material. This issue is crucial in the automotive industry, where DSRC was recently introduced for safety relevant vehicle-to-vehicle communication. For 


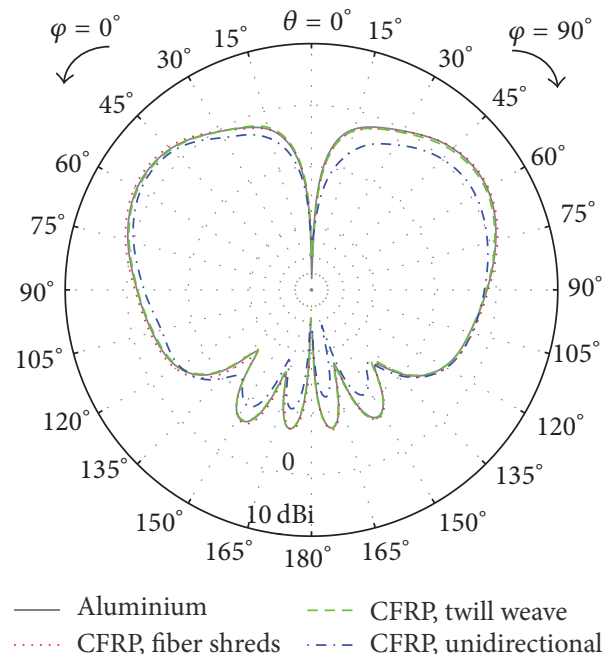

(a) $2 \mathrm{GHz}$

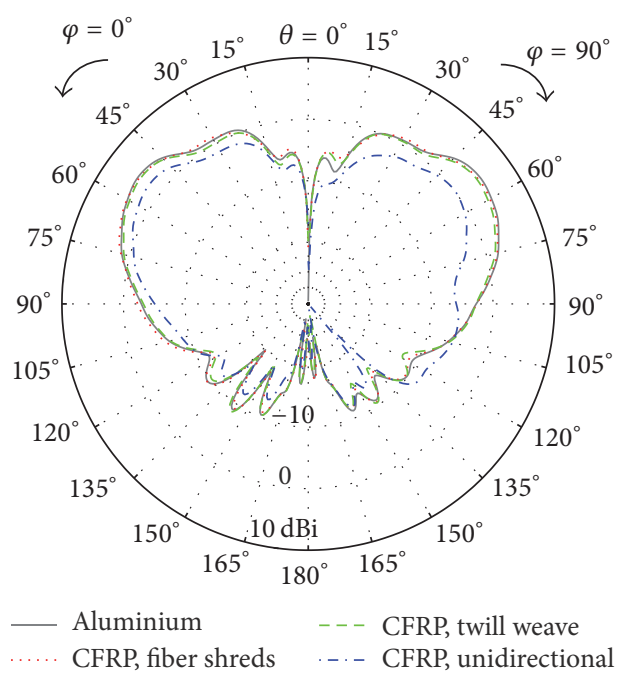

(b) $5 \mathrm{GHz}$

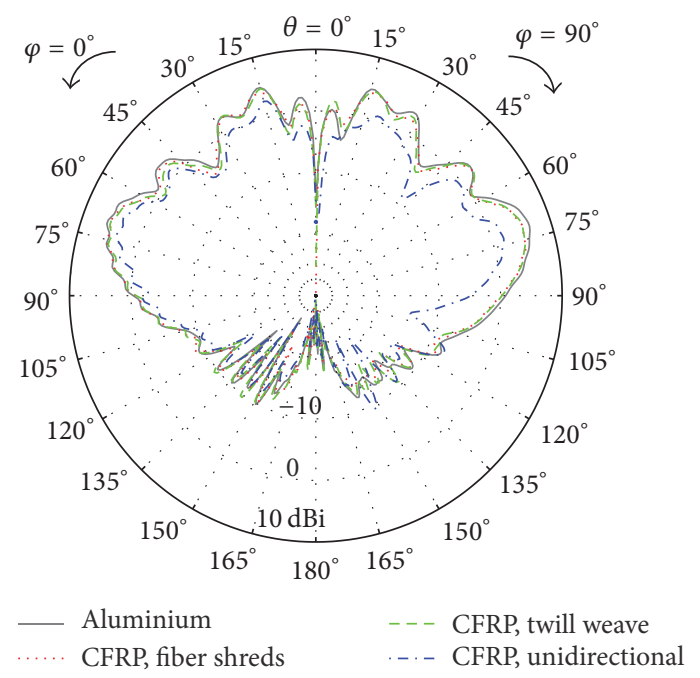

(c) $10 \mathrm{GHz}$

FIGURE 15: Vertical cuts of the gain patterns. Cuts for azimuthal angle $\varphi=0^{\circ}$ and $\varphi=90^{\circ}$ are shown on the left and right side, respectively (reprinted with permission from [35]; (C2017 IEEE).

electric car construction with a lightweight CFRP chassis, the materials should be chosen such that they do not impair antenna performance. The presented measurements show that this is achievable by placing either randomly oriented fiber shreds or woven fibers on top of any CFRP laminate. The electric currents are confined to the top most layer of the composite due to the skin effect. It is therefore feasible to only manufacture the top CFRP layer according to antenna considerations, whereas the remaining plies are designed to meet the mechanical requirements.

The antenna performance differences between shredCFRP, twill-CFRP, and aluminum in the investigated frequency range are negligible in most antenna applications. The conductivity of the CFRP with the shredded fibers seems to be even somewhat more isotropic than the conductivity of the twill-CFRP. Using recycled and shredded carbon fibers is desirable from an antenna viewpoint.

\section{Conclusion}

Quasi-isotropic CFRP with shredded carbon fibers in random alignment on the top layer are proposed for antenna applications. A CFRP laminate with carbon fiber shreds on top, but unidirectional fibers in the remaining plies, was manufactured. Carbon fiber shreds can be sourced from recycled CFRP, resulting in a sustainable product design.

Material measurements with the Nicolson-Ross-Weir (NRW) method show that the radio-frequency properties of the proposed CFRP are close to isotropic in comparison to unidirectional and woven CFRP. The variations in measured material parameters can be explained by inhomogeneity in the medium, rather than anisotropies.

Measurements of monopole antennas on the shreddedfiber CFRP show no influence on the antenna's gain pattern. Radiation efficiency of a conical monopole antenna on a 
ground plane made from the proposed CFRP is close to $100 \%$.

When being utilized as a ground plane material for antennas for IEEE 802.11p at $5.9 \mathrm{GHz}$, the shredded-fiber CFRP can be modeled as an isotropic material.

\section{Disclosure}

The current address of P. K. Gentner is Kathrein.

\section{Conflicts of Interest}

The authors declare that there are no conflicts of interest regarding the publication of this paper.

\section{Acknowledgments}

This work has been funded by the Christian Doppler Laboratory for Wireless Technologies for Sustainable Mobility. The financial support by the Federal Ministry of Economy, Family and Youth and the National Foundation for Research, Technology and Development is gratefully acknowledged. The authors acknowledge the TU Wien University Library for financial support through its Open Access Funding Program.

\section{References}

[1] S. Rea, D. Linton, E. Orr, and J. Mcconnell, "Electromagnetic shielding properties of carbon fibre composites in avionic systems," Microwave Review, pp. 29-32, 2005.

[2] D. Micheli, S. Laurenzi, V. M. Primiani, F. Moglie, G. Gradoni, and M. Marchetti, "Electromagnetic shielding of oriented carbon fiber composite materials," in Proceedings of the ESA Workshop on Aerospace EMC, pp. 1-5, 2012.

[3] M. D. Belrhiti, S. Bri, A. Nakheli, and A. Mamouni, "Dielectric properties by rectangular waveguide," International Journal of Emerging Sciences, vol. 3, no. 2, pp. 163-171, June 2013.

[4] W. van Rossum, F. Nennie, D. Deiana, A. J. van der Veen, and S. Monni, "Dielectric characterisation of human tissue samples," in Proceedings of the 8th European Conference on Antennas and Propagation, EuCAP 2014, pp. 594-598, April 2014.

[5] K. C. Yaw, "Measurement of dielectric material properties application note products," Application Note Rhode and Schwarz, 36 pages, 2012.

[6] H. C. Kim and S. K. See, "Electrical properties of unidirectional carbon-epoxy composites in wide frequency band," Journal of Physics D: Applied Physics, vol. 23, no. 7, 1990.

[7] T. A. Ezquerra, M. T. Connor, S. Roy, M. Kulescza, J. FernandesNascimento, and F. J. Baltá-Calleja, "Alternating-current electrical properties of graphite, carbon-black and carbon-fiber polymeric composites," Composites Science and Technology, vol. 61, no. 6, pp. 903-909, 2001.

[8] A. Galehdar and K. Nicholson, "The conductivity of unidirectional and quasi isotropic carbon fiber composites," in Proceeding of the 40th European Microwave Conference, pp. 882-885, Septemper 2010.

[9] A. Galehdar, W. S. T. Rowe, K. Ghorbani, P. J. Callus, S. John, and C. H. Wang, "The effect of ply orientation on the performance of antennas in or on carbon fiber composites," Progress in Electromagnetics Research, vol. 116, pp. 123-136, 2011.
[10] A. Galehdar, K. J. Nicholson, P. J. Callus et al., "The strong diamagnetic behaviour of unidirectional carbon fiber reinforced polymer laminates," Journal of Applied Physics, vol. 112, no. 11, Article ID 113921, 2012.

[11] C. L. Holloway, S. Member, M. S. Sarto, and M. Johansson, "Analyzing carbon-fiber composite materials with equivalent-layer models," IEEE Transactions on Electromagnetic Compatibility, vol. 47, no. 4, pp. 833-844, 2005.

[12] G. Wasselynck, D. Trichet, B. Ramdane, and J. Fouldagar, "Interaction between electromagnetic field and CFRP materials: a new multiscale homogenization approach," IEEE Transactions on Magnetics, vol. 46, no. 8, pp. 3277-3280, 2010.

[13] S.-E. Lee, K.-S. Oh, and C.-G. Kim, "Electromagnetic characteristics of frequency selective fabric composites," Electronics Letters, vol. 42, no. 8, pp. 12-13, 2006.

[14] R. R. De Assis and I. Bianchi, "Analysis of microstrip antennas on carbon fiber composite material," Journal of Microwaves, Optoelectronics and Electromagnetic Applications, vol. 11, no. 1, pp. 154-161, 2012.

[15] A. Mehdipour, C. W. Trueman, A. R. Sebak, and S. V. Hoa, "Carbon-fiber composite T-match folded bow-tie antenna for RFID applications," in Proceedings of the IEEE International Symposium on Antennas and Propagation and USNC/URSI National Radio Science Meeting, APSURSI 2009, June 2009.

[16] A. Mehdipour, A. R. Sebak, C. W. Trueman, I. D. Rosca, and S. V. Hoa, "Advanced conductive carbon fiber composite materials for antenna and microwave applications," in Proceedings of the Joint IEEE International Symposium on Antennas and Propagation and USNC-URSI National Radio Science Meeting (APSURSI '12), July 2012.

[17] A. Mehdipour, A. R. Sebak, C. W. Trueman, I. D. Rosca, and S. V. Hoa, "Conductive carbon fiber composite materials for antenna and microwave applications," in Proceedings of the 29th National Radio Science Conference (NRSC '12), pp. 1-8, April 2012.

[18] D. Gray, K. Nicholson, K. Ghorbani, and P. Callus, "Carbon fibre reinforced plastic slotted waveguide antenna," in Proceedings of the Asia-Pacific Microwave conference, APMC 2010, pp. 307-310, December 2010.

[19] K. J. Nicholson, W. S. T. Rowe, P. J. Callus, and K. Ghorbani, "Split-ring resonator loading for the slotted waveguide antenna stiffened structure," IEEE Antennas and Wireless Propagation Letters, vol. 10, pp. 1524-1527, 2011.

[20] K. J. Nicholson, W. S. T. Rowe, P. J. Callus, K. Ghorbani, and T. Itoh, "Coaxial right/left-handed transmission line for electronic beam steering in the slotted waveguide antenna stiffened structure," IEEE Transactions on Microwave Theory and Techniques, vol. 62, no. 4, pp. 773-778, 2014.

[21] G. Lacy, "Development of a 15 metre diameter high performance, low cost radio antenna for the square kilometre array," in Proceedings of the 20th International Conference on Composite Materials, pp. 1-9, July 2015.

[22] K. M. Keen, "Gain-Loss Measurements on a Carbon-Fibre Composite Reflector Antenna," Electronics Letters, vol. 11, no. 11, pp. 234-235, 1975.

[23] S. Futatsumori, K. Morioka, A. Kohmura, M. Shioji, and N. Yonemoto, "Fundamental applicability evaluation of carbon fiber reinforced plastic materials utilized in millimeter-wave antennas," in Proceedings of the IEEE Conference on Antenna Measurements and Applications, CAMA 2014, pp. 1-2, 2014.

[24] G. Ghione and M. Orefice, "Inter-modulation products generation from carbon fibre reflector antennas," in Proceedings of the 
Antennas and Propagation Society International Symposium, vol. 23, pp. 153-156, June 1985.

[25] A. Mehdipour, T. A. Denidni, C. W. Trueman et al., "Mechanically reconfigurable antennas using an anisotropic carbon-fibre composite ground," IET Microwaves, Antennas \& Propagation, vol. 7, no. 13, pp. 1055-1063, 2013.

[26] G. Artner and R. Langwieser, "Performance of an automotive antenna module on a carbon-fiber composite car roof," in Proceedings of the 10th European Conference on Antennas and Propagation, EuCAP 2016, April 2016.

[27] G. Artner, R. Langwieser, R. Zemann, and C. F. Mecklenbräuker, "Carbon fiber reinforced polymer integrated antenna module," in Proceedings of the 2016 IEEE-APS topical conference on antennas and propagation in wireless communications (APWC '16), pp. 59-62, September 2016.

[28] G. Artner, R. Langwieser, and C. F. Mecklenbräuker, "Concealed CFRP vehicle chassis antenna cavity," IEEE Antennas and Wireless Propagation Letters, 2016.

[29] F. Teodorescu, H. Teodorescu, G. Stanca, D. Condurache, and R. S. Craciunoiu, "On the recycling of carbon fibers reinforced polymer matrix composites," in Proceedings of the 4th IASME/WSEAS International Conference on Energy, Environment, Ecosystems and Sustainable Development, EEESD 2008, pp. 294-297, June 2008.

[30] A. M. Nicolson and G. F. Ross, "Measurement of the intrinsic properties of materials by time-domain techniques," IEEE Transactions on Instrumentation and Measurement, vol. 19, no. 4, pp. 377-382, 1970.

[31] W. B. Weir, "Automatic measurement of complex dielectric constant and permeability at microwave frequencies," Proceedings of the IEEE, vol. 62, no. 1, pp. 33-36, January 1974.

[32] A. N. Vicente, G. M. Dip, and C. Junqueira, "The step by step development of NRW method," in SBMO/IEEE MTT-S International Microwave and Optoelectronics Conference, IMOC 2011, pp. 738-742, November 2011.

[33] C. A. Balanis and D. DeCarlo, "Monopole antenna patterns on finite size composite ground planes," IEEE Transactions on Antennas and Propagation, vol. 30, no. 4, pp. 764-768, 1982.

[34] G. Artner, R. Langwieser, G. Lasser, and C. F. Mecklenbräuker, "Effect of carbon-fiber composites as ground plane material on antenna performance," in IEEE-APS Topical Conference on Antennas and Propagation in Wireless Communications, APWC 2014, pp. 711-714, August 2014.

[35] G. Artner, R. Langwieser, and C. F. Mecklenbräuker, "Carbon fiber reinforced polymer as antenna ground plane material up to $10 \mathrm{GHz}$," in Proceedings of the European Conference on Antennas and Propagation, EuCAP 2017, pp. 1-5, March 2017. 


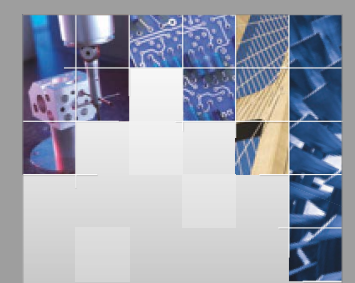

\section{Enfincering}
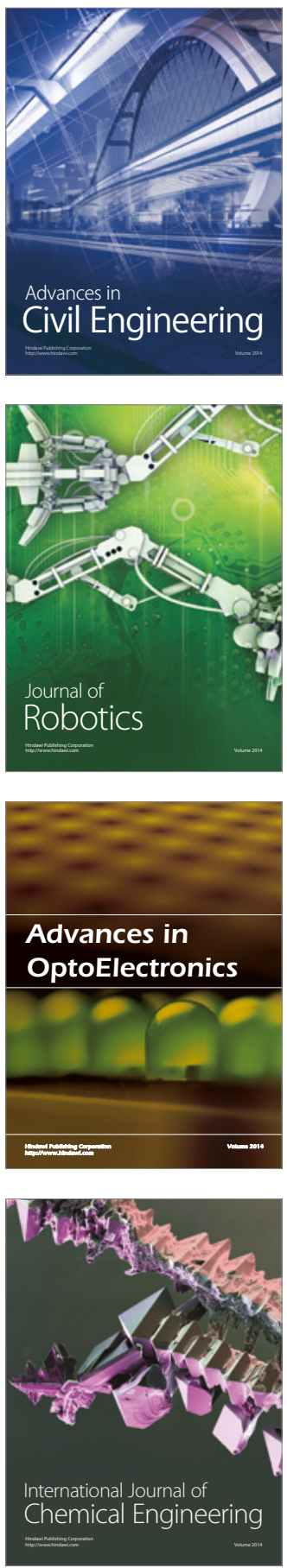

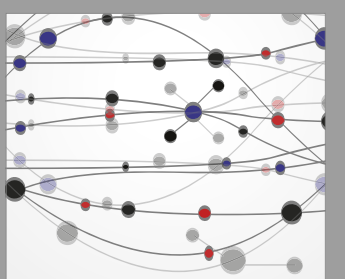

The Scientific World Journal

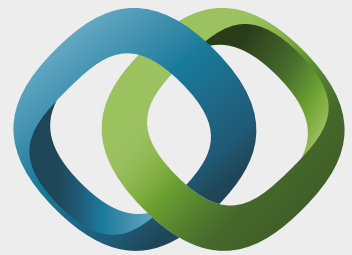

\section{Hindawi}

Submit your manuscripts at

https://www.hindawi.com
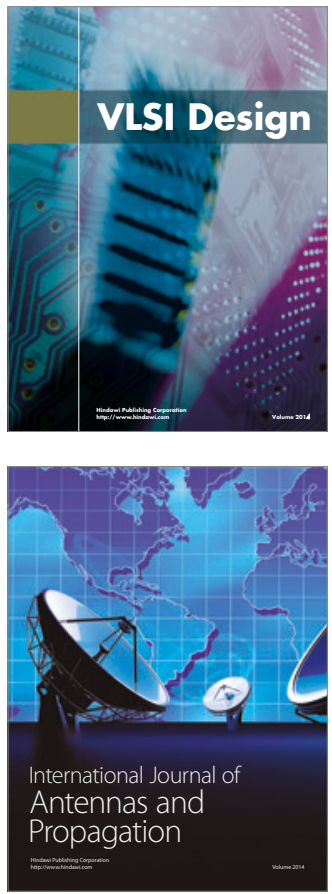

\section{Rotating}

Machinery
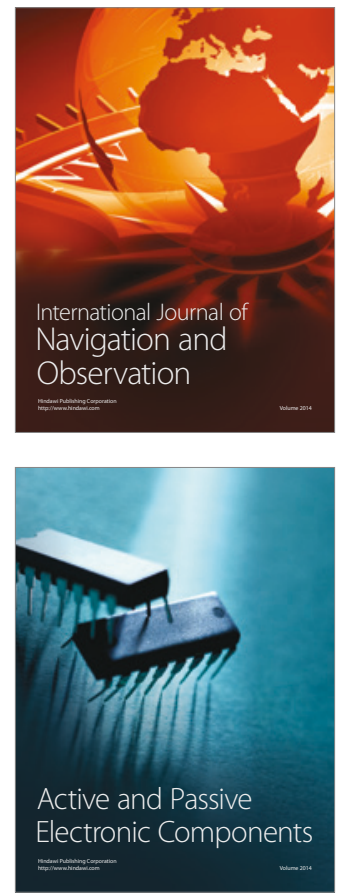
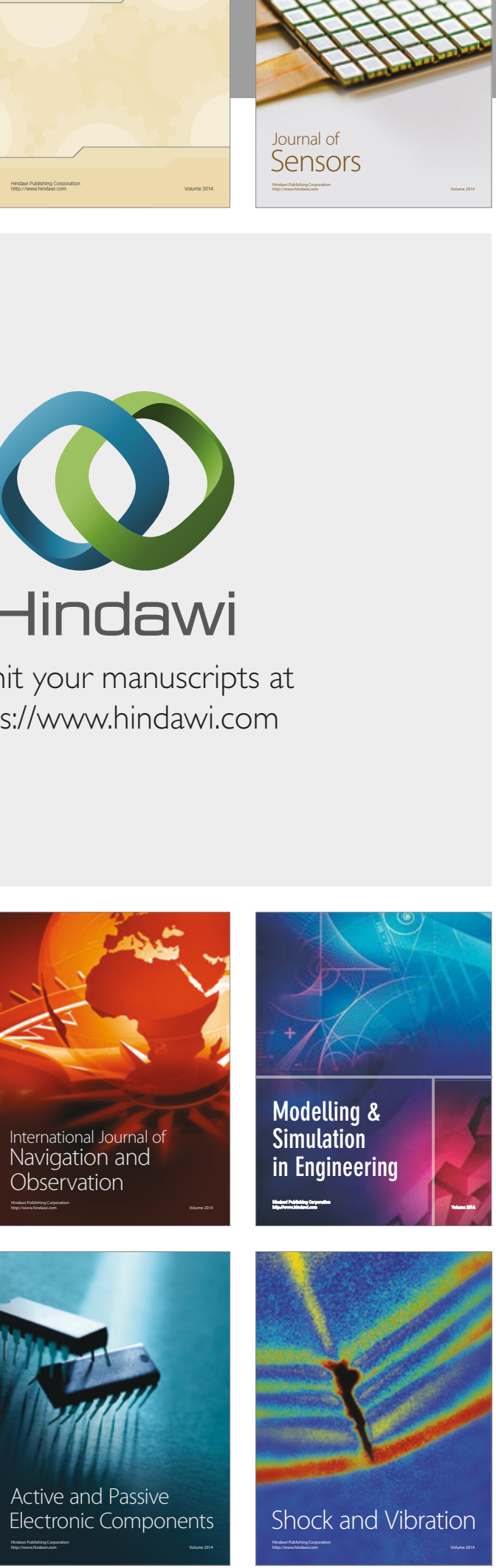
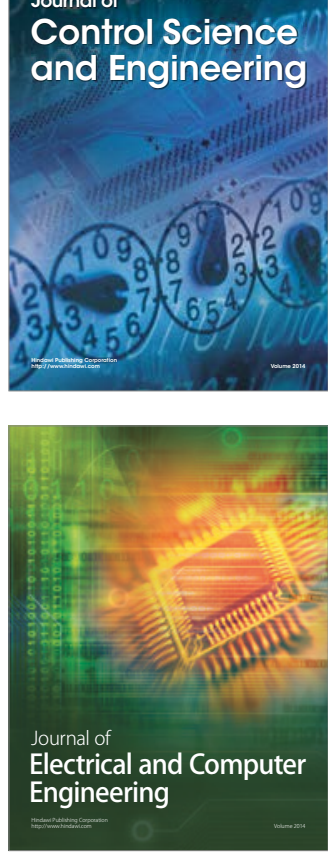

Distributed

Journal of

Control Science

and Engineering
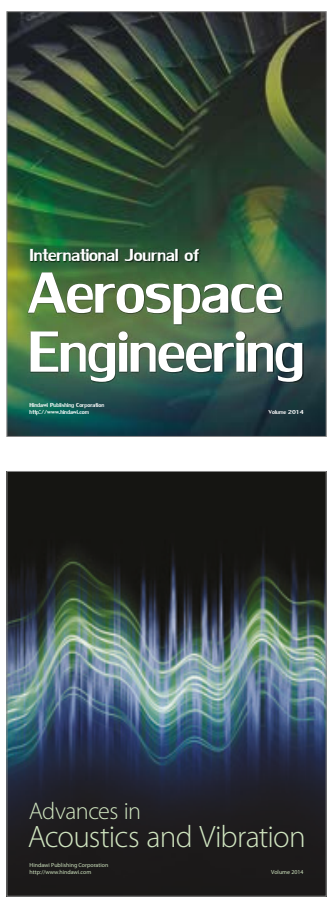

Sensor Networks 